\title{
IMPLEMENTASI DIGITAL MARKETING DALAM MENINGKATKAN OMSET PENJUALAN SUSU KAMBING ETAWA BUDIDAYA PESANTREN MASYHAD AN-NUR SUKABUMI
}

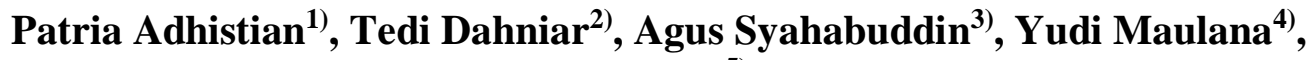 \\ Mairizal $^{5)}$ \\ 1,2,3,4,5 Program Studi Teknik Industri, Fakultas Teknik, Universitas Pamulang
}

\begin{abstract}
Abstrak
Ekonomi mandiri program pemberdayaan pondok pesantren untuk mngoptimalkan sumber daya salah satunya dengan budidaya susu kambing etawa untuk meningkatkan kesejahteraan pondok pesantren dan masyarakat lingkungan. Pengabdian didukung dengan menggunakan wawancara kepada pengurus, observasi lapangan, dan analisis dari data-data. Implementasi digital marketing sebagai sarana dan strategi penjualan dengan digital dan meningkatkan omset penjualan. Dengan pemberian informasi dan pengetahuan kepada pengurus pondok pesantren dan pemilihan design strategi penjualan online yang tepat. Oleh karena itu program implementasi digital marketing di Pondok Pesantern sebagai usaha meningkatkan omset penjualan budidaya susu kambing etawa. Pembinaan Berkelanjutan dengan menentukan strategi dan perencanaan digital marketing yang tepat salah satunya dengan menggunakan social media, disertai dengan optimisasi digital marketing tentunya bisa mendapatkan customer lebih dan omset penjualan dibandingkan dengan penjualan tradisional.
\end{abstract}

Keywords: digital marketing, strategi digital marketing, social media, omset penjualan

\begin{abstract}
The independent economy of the Islamic boarding school empowerment program to optimize resources, one of which is the cultivation of Etawa goat milk to improve the welfare of the boarding school and the environmental community. Community service is supported by using interviews with administrators, field observations, and analysis of data. Implementation of digital marketing as a means and strategy for digital sales and increasing sales turnover. By providing information and knowledge to the board of pesantren and choosing the right online sales strategy design. Therefore the digital marketing implementation program at Pondok Pesantren is an effort to increase sales turnover of Etawa goat milk cultivation. Sustainable coaching by determining the right digital marketing strategy and planning, one of which is by using social media, accompanied by digital marketing optimization, of course, can get more customers and sales turnover compared to traditional sales
\end{abstract}

Keywords: digital marketing, digital marketing strategy, social media, sales turnover 


\section{PENDAHULUAN}

\subsection{Latar Belakang}

Pondok Pesantren Masyhad An-Nur berada di Sukabumi, dengan jumlah santri ada 875 santri dan 355 santri menginap. dan mempunyai sekitar 55 pengasuh dan guru yang mendidik para santri. Pondok Pesantren Masyhad dibawah Yayasan AlMasyhad juga ada sekolah pendidikan tingkat SMP MTS dan SMA MA. Pesantren Masyhad sendiri mempunyai beberapa kewirausahaan bidang konveksi pembuatan baju koko, gamis dan beberapa baju muslim dan budidaya peternakan kambing Etawa dalam produksi susu kambing. Wirausaha dalam bidang konveksi baju muslim sudah sangat maju, dikarenakan banyak santri juga mengenakan pakaian muslim dan juga beberapa kerabat santri maupun guru yang berkunjung pasti membeli buah tangan berupa pakaian muslim.

Digital marketing merupakan usaha dalam pemasaran dengan brand atau image dari produk dengan menggunakan digital atau internet, dengan tujuan mendapatkan konsumen maupun calon konsumen dengan tepat waktu dan cepat. bentuk program promosi dan pencarian peluang pasar dengan menggunakan media digital online sebagai sarananya, contoh dengan menggunakan sosial media. Saat ini dunia maya atau internet diakses oleh banyak orang dari berbagai kalangan dan umur, sehingga potensi konsumen atau pelanggan adalah seluruh manusia dari seluruh dunia. Digital marketing terdiri dari pemasaran interaktif dan komprehensif yang memudahkan hubungan antara konsumen, distributor, dan produsen. Pada kondisi tertentu, digital marketing mampu memberikan kemudahan bagi pelaku usaha dalam melihat dan menyediakan segala kebutuhan calon konsumennya. Namun dilain pihak, calon konsumen pun dapat mencari dan mendapatkan informasi produk dan komoditi hanya dengan cara menjelajahi internet, sehingga memudahkan proses pencarian tersebut.

Dengan digital marketing pembeli atau customer ada di digital media, dan biasanya pelanggan sangat aktif social media, investasi lebih flexible disamping susu kambing etawa dijual di koperasi Pesantren Masyhad An-Nur, tidak perlu investasi tambahan jika ingin membuka cabang penjualan di toko-toko. Apalagi Indonesia mempunyai pelanggan digital terbanyak tercatat dari 2017

Tingginya animo masyarakat Indonesia dalam menggunakan berbagai fasilitas internet dan dunia maya dalam aktifitasnya, membuka peluang baru bagi perkembangan bisnis baik skala besar, menengah, kecil maupun mikro untuk mampu andil di dalamnya. Gambar 1 di bawah ini lebih rinci memperlihatkan bahwa ternyata $45 \%$ dari pengguna internet di Indonesia tersebut melakukan pencarian barang atau jasa secara online, $45 \%$ pengguna menggunjungi toko online, $31 \%$ pengguna melakukan transaksi online via komputer/laptop, dan 31\% pengguna melakukan transaksi online melalui perangkat mobile/smartphone mereka.

Berikut ini data penjualan kantung susu dan omset yang didapatkan tiap bulan dengan budidaya susu budidaya kambing etawa Pondok Pesantren Masyhad An-Nur. 
Implementasi Digital Marketing Dalam Meningkatkan Omset Penjualan Susu Kambing Etawa Budidaya

Tabel 1 Penjualan Susu Kambing Etawa Pondok Pesantren Masyhad An-Nur Sukabumi:

\begin{tabular}{|l|c|c|c|c|c|c|c|}
\hline \multirow{2}{*}{ Item } & \multicolumn{4}{|c|}{2019} & \multicolumn{4}{c|}{2020} \\
\cline { 2 - 8 } & September & November & Desember & Januari & Februari & Maret & April \\
\hline kantung susu & 1.825 & 1.796 & 1.805 & 1.788 & 1.564 & 658 & 511 \\
\hline Omset & 9.125 .000 & 8.980 .000 & 9.025 .000 & 8.940 .000 & 7.820 .000 & 3.290 .000 & 2.555 .000 \\
\hline
\end{tabular}

Penjualan susu kambing etawa menurun bersamaan dengan masa pandemik efek covid-19, dimana para santri semua dirumahkan dan hanya beberapa santri yang masih tinggal di Pondok Pesantren Masyhad An-Nur Sukabumi.

Penjualan susu kambing etawa akan diimplementasi dibeberapa channel distribusi maupun social media electronic melalui jaringan internet, dimana pasar tidak hanya masyarakat sekitar Pondok, namun bisa juga skala Kota Sukabumi dan Indonesia pada umumnya, diharapkan bisa meningkatkan omset penjualan dari susu kambing etawa.

Pengenalan dan distribusi ilmu tentang strategi digital marketing bidang peternakan khususnya susu kambing etawa ini diberikan melalui berbagai sesi pelatihan dan pendampingan yang komprehensif di lapangan bersama pengasuh, guru dan beberapa santri Pondok Pesantren Masyhad An-Nur Sukabumi, sehingga pengabdian masyarakat ini kami beri judul "Implementasi Digital Marketing dalam Meningkatkan Omset Penjualan Susu Kambing Etawa Budidaya Pesantren Masyhad An-Nur Sukabumi".

\subsection{Tinjauan Pustaka}

\subsubsection{Digital Marketing}

Pemasaran adalah suatu rangkaian kegiatan dalam memenuhi kebutuhan dan kepuasan konsumen. Dengan cara membuat produk, menentukan harga, tempat dan mempromosikan produk kepada konsumen. "Marketing as the process by which companies create value for customers and build strong customer relationships in order to capture value from customers in return", artinya pemasaran sebagai proses dimana suatu perusahaan membangun hubungan dengan pelanggan dan menciptakan nilai bagi pelanggan untuk membuat nilai bagi pelanggan sebagai imbalan (Rumondor, 2017)

"Marketing is a social process involving the activities necessary to enable iondividuals and organizations to obtain what they need and want through exchange with others and to develop on going exchange relationships (Muhiban, 2020), artinya pemasaran adalah suatu proses sosial yang melibatkan kegiatan baik individuals maupun organisasi untuk mendapatkan apa yang mereka butuhkan dan inginkan melalui proses pertukaran barang atau jasa dan mengembangkan hubungan pertukaran secara berkelanjutan.

Sedangkan digital marketing adalah kegiatan pemasaran yang dilakukan dengan memanfaatkan media digital, media sosial atau elektronik dengan melalui internet. Digital marketing sebagai sarana dalam menggunakan teknologi digital yang digunakan oleh suatu perusahaan atau produsen dalam memenuhi kebutuhan dari konsumen yang lebih efektif. (Dedi Purwana ES, 
2017). Adapun definisi yang lain "Pemasaran digital merupakan pendekatan pemasaran yang baru dan bukan hanya pemasaran tradisional yang diperkuat oleh elemen digital saja" (Mongkau, 2019)

\subsubsection{Dimensi Digital Marketing}

Dimensi digital marketing dari sisi promosi sebagai bagian pemasaran (4P) menurut (Prasetya, 2015) yaitu :

1). Website

Website adalah penghubung dengan dunia digital secara keseluruhan dan mungkin bagian yang paling penting dalam keseluruhan strategi pemasaran digital, dimana kegiatan online akan terarah langsung ke calon konsumen;

2). Optimalisasi Mesin Pencarian Digital (SEO)

Salah satu bagian penting dari website adalah SEO (Search Engine Optimation), atau proses pengaturan konten dari website agar mudah ditemukan oleh pengguna internet yang sedang mencari konten yang relevan dengan yang ada di website, dan juga menyajikan konten agar dapat dengan mudah ditemukan oleh mesin-mesin pencari;

3). Bisnis iklan berbayar (PPC advertising)

Periklanan PPC (Pay Per Click) dimana bisnis iklan dengan membayar pemasang iklan dari user yang meng-klik iklan atau advertise yang muncul dilayar atau halaman web atau aplikasi dengan menggunakan pencarian internet kata kunci tertentu.

4). Pemasaran afiliasi dan kemitraan strategis (Affiliate Marketing And Strategic Partnership)

Kegiatan pemasaran dengan kerjasama dengan organisasi/perusahaan penyedia website tertentu dalam mempromosikan produk atau layanannya;

5). Hubungan masyarakat online (Online PR)

Dengan menggunakan mediator dalam menyampaikan informasi dan memasarkan suatu produk atau jasa, biasanya dengan menggunakan blog, memfollow account media sosia, press release ataupun artikel (RSS) untuk menciptakan brand image dan informasi positif untuk orgranisasi atau perusahaan tersebut;

6). Jejaring sosial (social network)

Dengan menggunakan group media social atau komunitas, sehingga dapat lebih fokus dalam memasarkan dalam social network.

7). E-mail pemasaran (e-mail marketing)

Surat elektronik (e-mail) yang biasanya dilakukan secara broadcast kepada calon konsumen, dimana sarana ini masih menjadi andalan dalam memberikan informasi untuk memasarkan produk atau jasa;

8). Manajemen hubungan konsumen (Customer Relationship Management)

Menyediakan media kontak dan saran adalah sarana berkelanjutan untuk mendapatkan masukan dari konsumen. 


\subsubsection{Media Sosial}

Menurut Maoyan dalam (Indika, 2017) media sosial adalah penggunaan jaringan teknologi dalam menciptakan berita untuk pengguna internet dan mendeskripsikan informasi dan mengkomunikasikan, sedangkan pemasaran media sosial adalah suatu model pemasaran internet dalam mencapai tujuan pemasaran dengan menggunakan media sosial sebagai sarananya.

Sedangakan menurut Stockdale, Ahmed, dan Scheepers dalam (Dedi Purwana ES, 2017) media sosial adalah suatu aplikasi atau web yang berbasis internet berdasarkan teknologi dari Web 2.0 yang memungkinkan pertukaran user generated content dan pernciptaannya. Atau dengan kata lain alat komunikasi secara online melalui internet untuk mencari informasi yang tidak dibatasi antara pengguna dan media social yang lain.

Menurut Gunelius dalam (WIRO, 2017) manfaat dari sosial media marketing, yaitu:

1). Membangun hubungan antara konsumen dan produsen (Relaltionship Building)

Manfaat dari pemasaran dengan menggunakan social media, membangun hubungan baik untuk pengguna media sosial, konsumen maupun produsen dengan komunikasi lebih efektif dan efisien;

2). Membangun merek produk atau jasa (Brand Building)

Pembicaraan dimedia sosial biasanya sarana dalam promosi produk atau jasa sehingga dapat meningkatkan brand image, brand awareness, brand recognition dan recall, serta meningkatkan brand loyalty.

3). Publisitas (Publicity)

Pemasaran media sosial mempublikasikan suatu produk dan jasanya sehingga informasi dapat tersebar ke seluruh penjuru dunia dengan media internet online;

4). Promotions (Promosi)

Pemasaran media social juga mempromosikan suatu produk atau jasa, dengan memberikan penawaran khusus atau diskon bagi calon konsumennya, hal ini mendukung untuk menggaet calon konsumen baru dalam jejaring media sosial.

5). Market Reseacrh (Riset Pasar)

Media Sosial digunakan sebagai sarana dalam analisis pasar, seberapa besar tingkat pasar, kebutuhan yang diinginkan oleh calon pembeli, dan melihat kompetitor dalam menawarkan produk/jasanya.

\section{METODE PELAKSANAAN}

\subsection{Kerangka Pemecahan Masalah}

Berikut kerangka pikir dalam pemecahan masalah dengan "Implementasi Digital Marketing dalam Meningkatkan Omset Penjualan Susu Kambing Etawa Budidaya Pesantren Masyhad An-Nur Sukabumi".

Untuk lebih jelasnya dapat dilihat dalam skema di bawah ini: 


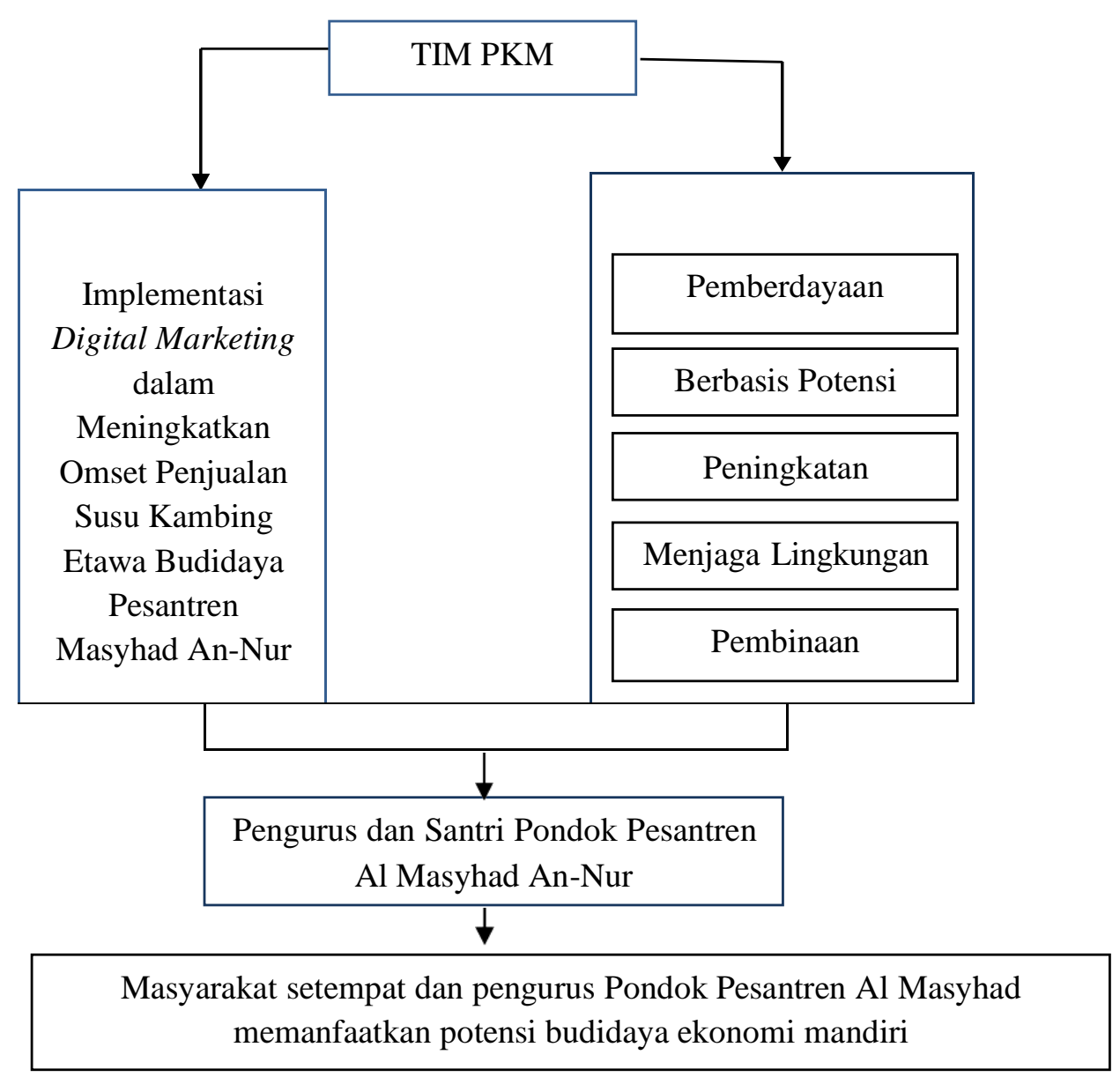

Gambar 1 Skema Kerangka Pemecahan Masalah

\subsection{Metode Pelaksanaan}

Dalam menjalankan program kami, ada beberapa metode pelaksanaan teknis yang dilakukan, diantaranya sebagai berikut:

1). Penjalinan kerja sama dengan Organisasi Masyarakat dan pengurus pondok pesantren yang membidangi ekonomi kreatif dan wirausaha mandiri dalam lingkungan pondok pesantren

2). Melakukan Sosialisasi kegiatan bisnis dilingkungan pondok pesantren al mashad sukabumi jawa barat. Dan memberikan pemahaman bisnis digital atau digital marketing

3). Pelaksanaan pembuatan sarana social media untuk susu kambing etawa budidaya Pondok Pesantren dan pelatihan e-comerce pada platform yang sudah ada seperti Lazada, tokopedia, bukalapak dll

4). Penunjukan operator website sebagai admin dalam lingkungan Pondok Pesantren Al Mashad Annur Sukabumi Jawa Barat

5). Peninjauan hasil kerja sarana social media dan progres perkembangan penjualan susu kambing etawa secara offline di Pondok Pesantren Al Mashad Annur Sukabumi Jawa Barat 
6. Analisis dan evaluasi dampak kegiatan pembuatan sarana social media ini terhadap peningkatan penjualan susu kambing etawa dan baju muslim yang di budidayakan oleh Pondok Pesantren Al Mashad Annur Sukabumi Jawa Barat

\subsection{Biaya Pelaksanaan Pengabdian Kepada Masyarakat}

Tabel 2 Biaya Pelaksanaan Pengabdian Kepada Masyarakat

\begin{tabular}{|c|c|c|c|c|}
\hline $\begin{array}{c}\text { Jenis } \\
\text { Pembelanjaan }\end{array}$ & Item & Volume & $\begin{array}{c}\text { Satuan } \\
\text { Biaya (Rp) }\end{array}$ & Total (Rp) \\
\hline Belanja Bahan & Kertas HVS & 3 & 50.000 & 150.000 \\
\hline Belanja Bahan & Materi Pelatihan & 60 & 20.000 & 1.200 .000 \\
\hline Belanja Bahan & Fotocopy & 300 & 100 & 30.000 \\
\hline Belanja Bahan & Sertifikat & 15 & 10.000 & 150.000 \\
\hline Belanja Bahan & $\begin{array}{l}\text { Pembuatan } \\
\text { Proposal dan } \\
\text { Laporan }\end{array}$ & 6 & 75.000 & 450.000 \\
\hline Belanja Bahan & Materai & 5 & 30.000 & 150.000 \\
\hline Belanja Bahan & Bolpoint & 7 & 20.000 & 140.000 \\
\hline $\begin{array}{l}\text { Belanja Barang } \\
\text { Non Opreasional }\end{array}$ & $\begin{array}{l}\text { Banner }(3 \text { meter } X \\
1,5 \text { meter })\end{array}$ & 1 & 200.000 & 200.000 \\
\hline $\begin{array}{l}\text { Belanja Barang } \\
\text { Non Opreasional }\end{array}$ & $\begin{array}{l}\text { Plakat kenang- } \\
\text { kenangan TIM } \\
\text { PKM UNPAM ke- } \\
\text { KSM }\end{array}$ & 1 & 395.000 & 395.000 \\
\hline $\begin{array}{l}\text { Belanja Barang } \\
\text { Non Opreasional }\end{array}$ & $\begin{array}{l}\text { Publikasi dimedia } \\
\text { social }\end{array}$ & 1 & 500.000 & 500.000 \\
\hline $\begin{array}{l}\text { Belanja Barang } \\
\text { Non Opreasional }\end{array}$ & $\begin{array}{l}\text { Publikasi artikel } \\
\text { ilmiah (jurnal) }\end{array}$ & 1 & 500.000 & 500.000 \\
\hline Belanja Perjalanan & Makan peserta & 50 & 25.000 & 1.250 .000 \\
\hline Belanja Perjalanan & Makanan panitia & 15 & 25.000 & 375.000 \\
\hline Belanja Perjalanan & Air Mineral & 4 & 20.000 & 80.000 \\
\hline Belanja Perjalanan & Snack & 65 & 10.000 & 650.000 \\
\hline Belanja Perjalanan & $\begin{array}{l}1 \text { kali kunjungan } \\
\text { (saat survey awal) }\end{array}$ & 4 & 200.000 & 800.000 \\
\hline Belanja Perjalanan & $\begin{array}{l}1 \text { kali kunjungan } \\
\text { (saat penyuluhan } \\
\text { dan pelatihan) }\end{array}$ & 15 & 150.000 & 2.250 .000 \\
\hline Total Pembiayaan & & & & Rp9.270.000 \\
\hline
\end{tabular}




\section{HASIL DAN PEMBAHASAN}

\subsection{Materi Pelaksanaan Pengabdian Kepada Masyarakat}

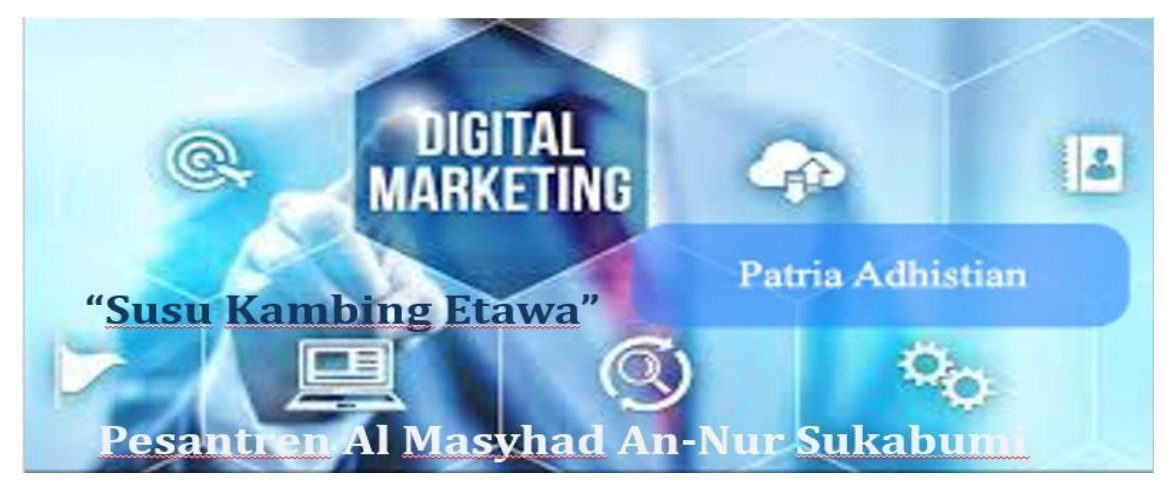

Gambar 1 Materi Pelaksanaan Pengabdian Masyarakat

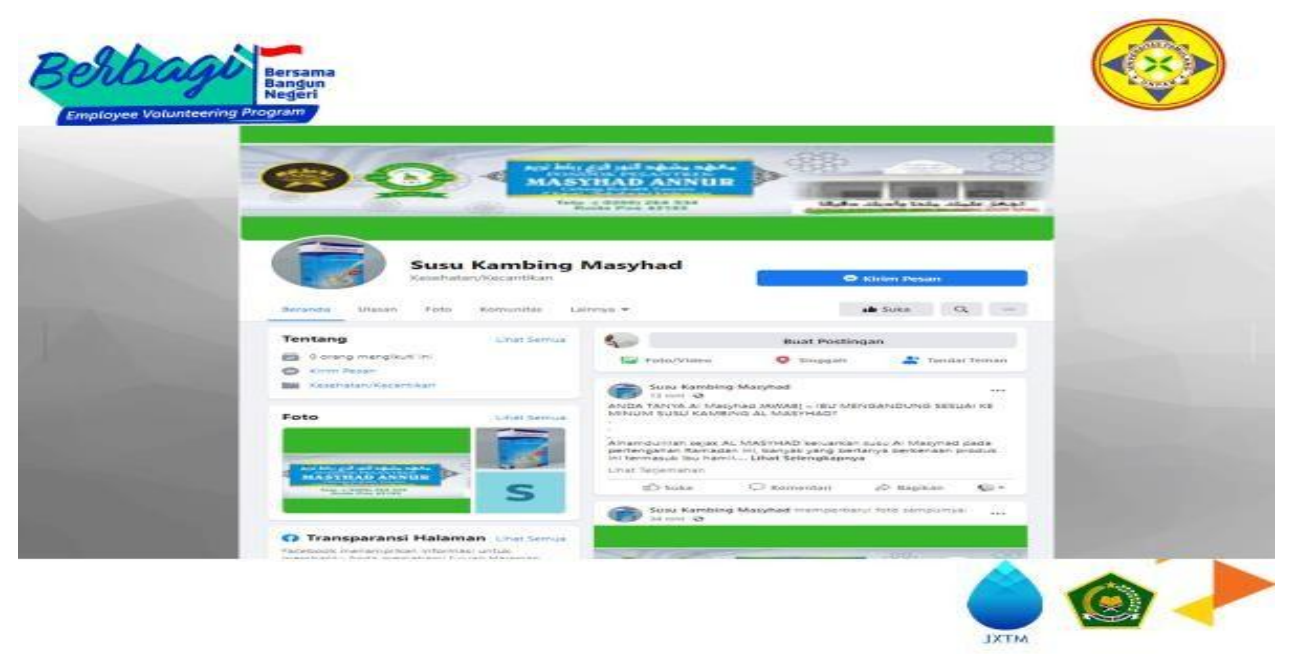

Gambar 2 Materi Pelaksanaan Pengabdian Masyarakat

\subsection{Hasil Pengabdian Kepada Masyarakat}

Berdasarkan hasil analisis dan laporan kunjungan secara offline (sebulan) setelah pelaksanaan pengabdian masyarakat terlihat adanya peningkatan omset dan daya beli masyarakat sekitar terhadap susu kambing Etawa hasil budidaya Pondok Pesantren Al Masyhad Annur Sukabumi. 


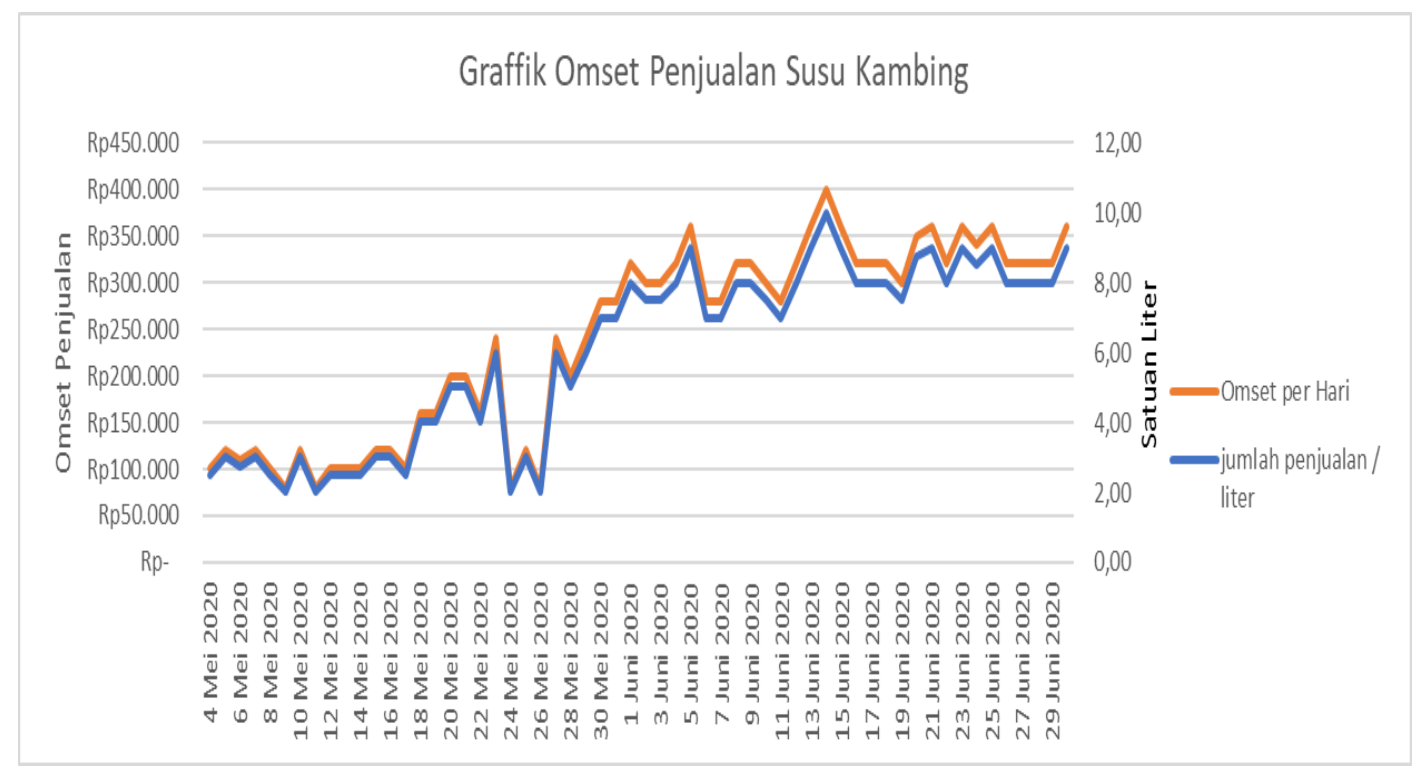

Gambar 3 Grafik Daya Minat Masyarakat Berwirausaha

Terlihat dari grafik maksimum omset sekitar Rp 360.000,00 dengan asumsi rata produksi susu sekitar 7,5 liter per hari dan harga perliter Rp 40.000 dengan jumlah kambing hanya 54 ekor. Karena keterbatasan jumlah kambing yang tersedia di kandang pesantren.

Table 3 Rata-rata keuntungan dan efisiensi usaha pada pengolahan susu

\begin{tabular}{|l|cc|}
\hline \multicolumn{1}{|c|}{ Uraian } & \multicolumn{2}{c|}{ Nilai } \\
\hline Rata-rata omset Harian & $\mathrm{Rp}$ & 240.000 \\
\hline biaya tenaga kerja & $\mathrm{Rp}$ & 100.000 \\
\hline Biaya lain-lain & $\mathrm{Rp}$ & 10.000 \\
\hline Rata-rata keuntungan & $\mathrm{Rp}$ & 130.000 \\
\hline Effisiensi usaha & & 2,18 \\
\hline
\end{tabular}

Efisiensi Usaha Efisiensi merupakan ukuran dalam mencapai produksi yang didapat dari suatu kesatuan biaya, kemudian input-output ratio yang juga dapat dijadikan dasar dalam menentukan nilai efisiensi apabila nilai efisiensi usaha (R/C) $>1$, dalam hal ini apabila nilai efiensi lebih dari satu maka usaha dikatakan sudah efisien dan juga semakin besar pula keuntungan yang akan diperoleh. Nilai efisiensi usaha pengolahan susu pasteurisasi di KMS diperoleh dengan membagi penerimaan dengan biaya produksi. Dari Tabel 4 diketahui bahwa nilai rata-rata efisiensi usaha yang diperoleh pada usaha pengolahan susu kambing di Pondok Pesantren $\mathrm{Al}$ Masyhad An-Nur dapat dikatakan efisien karena nilainya 2,18. 


\section{SIMPULAN}

Berdasarkan hasil pelaksanaan kegiatan pengabdian kepada masyarakat oleh Lembaga Penelitian dan Pengabdian Masyarakat (LPPM) dan Dosen Program Studi Teknik Industri Universitas Pamulang adalah sebagai berikut:

1). Memodelkan digital marketing untuk budidaya susu kambing etawa Pondok Pesantren Al Masyhad An-Nur Sukabumi dengan menggunakan social media online baik facebook market dan instagram.

2). Effisiensi usaha dalam budidaya susu kambing etawa dengan nilai rata-rata effisiensi usaha secara hari adalah 2,18 dan rata-rata keuntungan harian adalah $\mathrm{Rp}$ $130.000,00$

3). Setelah melakukan Pengabdian Masyarakat diketahui Faktor pendukung penjualan susu kambing etawa ialah: pemberdayaan santri dan masyarakat sekitar sehingga bisa menurunkan biaya harian, Sumber daya alam yang melimpah dengan rumput sebagai sarana pakan kambing, sarana yang sudah memadai. Sedangkan Faktor Penghambat adalah daya tahan susu hanya bertahan $4-6$ jam di udara bebas, jumlah kambing yang terbatas hanya 54 ekor, masih tradisional pengemasan.

Berdasarkan hasil kesimpulan di atas maka pengabdi memberikan saran untuk meningkatkan jumlah omset penjualan perlu adanya sarana produksi dan pengemasan yang lebih baik serta adanya inovasi agar daya tahan susu lebih lama dengan pengolahan susu cair menjadi bubuk.

\section{DAFTAR PUSTAKA}

Fawaid, A. (2017). Pengaruh Digital Marketing System, terhadap Daya Saing Penjualan Susu Kambing Etawa. Jurnal Ekonomi dan Perbankan Syariah "Iqtishadia". PISSN: 2354-7057: E-ISSN: 2442-3076. Vol. 4 No. 1, Juni 2017.

Pradiani, T. (2017). Pengaruh Sistem Pemasaran Digital Marketing terhadap Peningkatan Volume Penjualan Hasil Industri Rumahan. JIBEKA Vol. 11 No. 2, Februari 2017: 46 - 53.

Silvia, B. S. (2006). Internet Marketing: Konsep dan Persoalan Baru Dunia Pemasaran. Jurnal Manajemen Vol. 6 No. 1, November 2006.

Yadaf M, Y. Joshi, Z. Rahman. (2015). Mobile Social Media: The New Hybrid Element of Digital Marketing Communication. Procedia-Social and Behavioral Sciences. 189 (2015) 335-343. Elsevier

Coviello, N., Milley, R. and Marcolin, B. (2001). Understanding IT-enabled interactivity in contemporary marketing. Journal of Interactive Marketing, Vol.15 No. 4, pp. 1833.

Heidrick dan Struggles. (2009). Heidrick \& Struggles CEO. China: China Marketing Press

Sanjaya, Ridwan dan Josua Tarigan. (2009). Creative Digital Marketing. Jakarta: PT Elex Media Komputindo.

Samuelson, P. A. Economics, Ninth Edition. (1973). Tokyo: Mc. Graw - Hill Kongasukha Ltd.

Soetomo. (2013). Pemberdayaan Masyarakat. Yogyakarta: Pustaka Pelajar.

Tahziduhu, N. (2002). Pengantar Teori Pengembangan Sumber Daya Manusia. Jakarta: PT Renika Cipta. 